\title{
How to use a controlled fast to investigate hypoglycaemia
}

\author{
S Sreekantam, ${ }^{1}$ M A Preece, ${ }^{2}$ S Vijay, ${ }^{1}$ J Raiman, ${ }^{1}$ S Santra ${ }^{1}$
}

\begin{abstract}
${ }^{1}$ Department of Metabolic Medicine, Birmingham Children's Hospital, Birmingham, UK ${ }^{2}$ Department of Newborn Screening and Biochemical Genetics, Birmingham Children's Hospital, Birmingham, UK
\end{abstract}

\section{Correspondence to}

Dr S Santra, Department of Metabolic Medicine, Birmingham Children's Hospital, Birmingham B4 6NH, UK:

saikat.santra@bch.nhs.uk

Accepted 1 July 2016 Published Online First 24 August 2016

\section{CrossMark}

To cite: Sreekantam $S$, Preece MA, Vijay $S$, et al. Arch Dis Child Educ Pract Ed 2017:102:28-36.

\begin{abstract}
Controlled fasts can play a valuable role in the diagnosis and management of hypoglycaemia in paediatric clinical practice, but are no substitute for the collecting of appropriate critical samples at the time of hypoglycaemia for metabolic and endocrine studies. Fatty acid oxidation defects, hyperinsulinism and adrenal insufficiency should always be excluded prior to organising controlled fasts. Controlled fasts are safe if conducted in an experienced setting with strict protocols in place. Failure to adhere to protocol can defeat the purpose of the study and can potentially be dangerous. Proper planning in conjunction with the laboratory and close supervision by staff experienced in controlled fasts is crucial to ensure the best quality information is yielded from these procedures.
\end{abstract}

\section{INTRODUCTION}

Hypoglycaemia is not infrequent in paediatric clinical practice and can potentially result in significant morbidity and mortality. ${ }^{1-3}$ Some metabolic and endocrine disorders can cause recurrent hypoglycaemia in childhood and these might be potentially preventable.

Controlled fasts are used to evaluate hypoglycaemia safely in a hospital setting. The aim of this article is to help paediatricians understand the role of controlled fasts in the investigation and management of hypoglycaemia.

\section{WHAT IS THE DEFINITION OF HYPOGLYCAEMIA?}

There is no agreement between paediatricians and among paediatric textbooks about the lowest safe blood glucose levels in childhood. The definition of hypoglycaemia should ideally be based upon the lowest levels at which normal neurological function is affected. This varies between individuals, and depends on several factors including the rate of fall in blood glucose, the properties of the glucose transporter GLUT1 (which transports glucose across the blood-brain barrier), variation in individual neural susceptibility to low glucose concentrations and the ability of neurons to use ketone bodies for energy production. Nevertheless, it has been shown that neurological dysfunction in newborns and children does not occur until plasma glucose levels fall below $2.6 \mathrm{mmol} / \mathrm{L},{ }^{4} 5$ and this can be used as reasonable value for defining significant hypoglycaemia in childhood. In practice, we recommend prompt treatment of hypoglycaemia if plasma glucose falls below $3 \mathrm{mmol} / \mathrm{L}$ in asymptomatic patients and in patients with symptomatic hypoglycaemia regardless of the result. ${ }^{6-9}$

Metabolic and endocrine disorders causing hypoglycaemia in childhood (boxes 1 and 2) and tests recommended for investigation of hypoglycaemia (table 1) are outlined below.

\section{PHYSIOLOGICAL BACKGROUND}

Normal adaptive mechanisms during fasting

During fasting, blood glucose levels are sustained as a result of adaptive hormonal and metabolic counter regulatory mechanisms.

In the early fasting state, insulin levels decrease and levels of the counterregulatory hormones glucagon, growth hormone and cortisol increase. Glucagon stimulates glycogenolysis to release glucose from liver glycogen. When glycogen stores are depleted, glucose is formed from amino acids and glycerol by gluconeogenesis.

Insulin inhibits lipolysis which is activated in the fasting state to release free fatty acids, which are subsequently $\beta$-oxidised resulting in the generation of ketones. An increase in metabolites such as free fatty acids may precede hypoglycaemia. Ketone bodies, namely acetoacetate and 3-hydroxybutyrate are used as an alternative source of energy. ${ }^{10}$

The occurrence and intensity of ketonaemia is proportionate to the extent of hypoglycaemia. ${ }^{10} 11$ 
Box 1 Metabolic causes of hypoglycaemia in

childhood

- Glycogenoses

Glycogen storage diseases (I, III, VI, IX)

Glycogen synthase deficiency (GSD 0)

- Glucose transporter defects

- Fanconi-Bickel syndrome

- Gluconeogenesis disorders

- Fructose-1,6-bisphosphatase deficiency

Glucose-6-phosphatase deficiency (GSD 1)

- Fatty acid oxidation disorders

- Primary carnitine deficiency and carnitine cycle defects

- MCADD, LCHADD, VLCADD

Multiple acyl-CoA dehydrogenase deficiency

- Ketone synthesis defects

HMG-CoA synthase and lyase deficiencies

- Ketone utilisation defects

SCOT, ACAT1, MCT1 deficiencies

- Hereditary fructose intolerance

- Mitochondrial respiratory chain defects

- Liver disease (eg, galactosaemia)

- Other conditions associated with hypoglycaemia: tyrosinemia type 1 and organic acidaemias (not common)

Ghosh et al. ${ }^{9}$

ACAT1, acetoacetyl-CoA thiolase; HMG-CoA lyase, hydroxymethylglutaryl-CoA lyase; HMG-CoA synthase, hydroxymethylglutaryl-CoA synthase; LCHADD, long chain hydroxy acyl-CoA dehydrogenase deficiency; MCADD, medium chain acyl-CoA dehydrogenase deficiency; MCT1, monocarboxylase transporter 1; SCOT, succinyl-CoA oxoacid transferase; VLCADD, very long chain acyl-CoA dehydrogenase deficiency.

In the fed state, insulin levels increase which switches off lipolysis leading to a fall in the level of ketone bodies.

A typical example of the metabolic changes seen during a prolonged fast in a 3-year-old child is shown in figure 1.

Consequently, a disturbance of any component of these responses has the potential to lead to hypoglycaemia. For instance in hyperinsulinism, high levels of insulin inhibit mobilisation of free fatty acids from adipose tissue and subsequent $\beta$-oxidation to ketones. These children typically have low levels of free fatty acids and ketone bodies at the time of hypoglycaemia. Defective $\beta$-oxidation of fatty acids in fatty acid oxidation defects explains the high levels of free fatty acids and hypoketotic hypoglycaemia noted in these children. In hepatic glycogen storage disorders, inability to mobilise glucose from liver glycogen explains the hypoglycaemia and very short fasting tolerance seen in these patients (figure 2A,C).
Box 2 Endocrine causes of hypoglycaemia in

childhood

- Hyperinsulinaemic hypoglycaemia

Hyperinsulinism-hyperammonaemia syndrome

Congenital hyperinsulinism

- Dumping syndrome

Insulinoma

- Beckwith-Wiedemann syndrome

- Exogenous insulin (diabetes, factitious hyperinsulinism)

- Adrenal insufficiency

- Primary adrenal insufficiency

- X-linked adrenoleukodystrophy

- Withdrawal of exogenous corticosteroids Hypopituitarism

- Growth hormone deficiency

Hypopituitarism

Isolated growth hormone deficiency

- Other causes

Idiopathic ketotic hypoglycaemia

Ghosh et al. ${ }^{9}$

The duration of fasting prior to hypoglycaemia can often provide clues to an underlying metabolic or endocrine disorder as shown in table 2.

\section{TECHNOLOGICAL BACKGROUND}

\section{Prerequisites for a controlled fast}

It is important to exclude fatty acid oxidation defects and hyperinsulinism before subjecting a child to a controlled fast. Fasting children with fatty acid oxidation defects and hyperinsulinism can be potentially life threatening as these subjects cannot produce ketone bodies. Blood acylcarnitine analysis should always be performed and confirmed to be normal before a controlled fast. Hyperinsulinism can be diagnosed based on high glucose requirements and detectable levels of insulin at the time of hypoglycaemia.

Suspected adrenal insufficiency should be assessed by a short Synacthen test prior to the fast.

\section{Setting}

Controlled fasts should be performed according to a strict protocol in a hospital setting under close supervision. The protocol should define the threshold for termination of the fast and initiation of appropriate treatment.

Controlled fasts should be planned in advance in conjunction with the laboratory. The protocol for the controlled fast should be individualised based on several factors including the clinical presentation, age of the patient and the reason for the fast. The duration of the fast depends on the age of the child (table 3) and the start time set such that in the event 

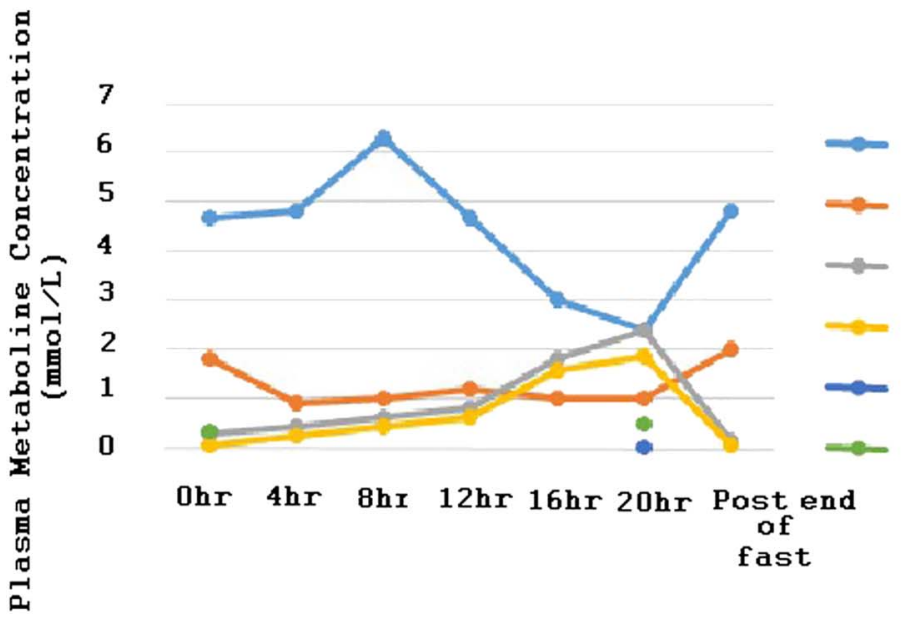

\section{Glucase}

Lactate

Free fatty acids

3Hydraxy butyrate

Insulin

Cortisol

Time from Start of Fast

Figure 1 Typical metabolic responses to a 20 hour fast in a normal 3 year old boy.

of hypogylcaemia occurring, it is expected to do so during routine working hours with optimal staff levels available, for example, a child aged 8-12 months starting fasting at midnight.

Patients may therefore need admission overnight according to the planned duration of the fast. The patient should be examined to ensure fitness to undergo the fast. If there are signs of intercurrent illness, the fast is better deferred until the child is well. A secure intravenous cannula must be inserted before commencing the fast to enable easy and prompt sampling without distressing the child and also to enable dextrose to be given quickly if hypoglycaemia needs treating.

During the fast, only plain water should be allowed if the child is thirsty. Specimens should be taken regularly along with bedside glucose measurements as per an individualised protocol (table 4). The clinical condition should be monitored carefully for signs of hypoglycaemia. For children admitted the night before, hourly sampling can commence at the start of the working day, that is, 08:00-16:00.

\section{When to stop the fast?}

If the patient is hypoglycaemic or symptomatic, an urgent lab glucose along with the end of fast samples should be collected and the fast terminated. In our practice, we terminate controlled fasts in an asymptomatic child if the glucometer reading and/or the true laboratory glucose reading is $\leq 3.0 \mathrm{mM}$.

If the patient is symptomatic, intravenous glucose should be given after the collection of end of fast samples as a slow bolus in a dose of $200 \mathrm{mg} / \mathrm{kg}$ ( $2 \mathrm{~mL} / \mathrm{kg}$ of $10 \%$ dextrose), followed by a continuous infusion of glucose at $5-8 \mathrm{mg} / \mathrm{kg} / \mathrm{min}$ until the patient is stable enough to tolerate oral feeds.

If the patient is asymptomatic, a meal or a high carbohydrate drink can be given.

Post end of fast samples should be taken $1-1.5$ hours later.
Why collect postprandial samples?

Collection of postprandial samples is important as it can provide useful diagnostic information.

Postprandial hyperglycaemia and fasting hypoglycaemia are seen in Fanconi-Bickel syndrome, characterised by mutations within GLUT2, the gene encoding the facilitative glucose transporter in hepatocytes, pancreatic $\beta$-cells, enterocytes and renal tubular cells. Analysis of postprandial glucose, lactate and ketones can be helpful in diagnosing rare metabolic conditions like glycogen synthase deficiency (GSD type 0), where postprandial lactate and glucose are usually elevated and ketone body utilisation defects like succinyl-CoA oxoacid transferase deficiency, where ketones are not always suppressed after feeding. Abnormalities in the postprandial metabolites warrant further metabolic input and investigations.

\section{EXAMPLES OF CONTROLLED FAST INTERPRETATION}

1) Glycogen storage disease type 1

A baby boy A aged 9 months with suspected glycogen storage disorder was electively admitted for a controlled fast to determine his safe fasting tolerance.

The results of this are shown in table 5 and figure $2 \mathrm{C}$. Looking at the results of the fast, it is clear that baby A had a low plasma glucose of $2.7 \mathrm{mmol} / \mathrm{L}$ at 2 hours $15 \mathrm{~min}$ from the commencement of the fast. The results also illustrate how important is it to get a true glucose sample and not to rely completely on bedside glucometer readings. Had the true glucose not been checked, this child may have been assumed to be safe to fast for 30 min longer than he actually is. His safe fasting tolerance is only 2 hours.

There is no appreciable ketotic response which is also frequently seen in GSD type 1.

\section{2) Ketotic hypoglycaemia}

A boy aged 3 years with recurrent episodes of hypoglycaemia secondary to illness was admitted for a controlled fast the results of which are shown in table 6 and figure $2 \mathrm{~B}$. 
Table 1 Tests recommended for investigation of hypoglycaemia/hypoglycaemia screen

\begin{tabular}{|c|c|c|c|c|}
\hline Test & $\begin{array}{l}\text { Sample requirements } \\
\text { (can vary-confirm } \\
\text { with your laboratory) }\end{array}$ & $\begin{array}{l}\text { Metabolic/endocrine } \\
\text { conditions screened for by } \\
\text { this test }\end{array}$ & $\begin{array}{l}\text { Collection at the } \\
\text { time of } \\
\text { hypoglycaemia }\end{array}$ & Notes \\
\hline Glucose & $\begin{array}{l}\text { Blood } \\
\text { Fluoride oxalate }\end{array}$ & All & Essential & $\begin{array}{l}\text { To confirm genuine } \\
\text { hypoglycaemia }\end{array}$ \\
\hline $\begin{array}{l}\text { Insulin and C } \\
\text { peptide }\end{array}$ & $\begin{array}{l}\text { Blood } \\
\text { Serum }\end{array}$ & $\begin{array}{l}\text { Hyperinsulinism (including } \\
\text { factitious) } \\
\text { HIHA }\end{array}$ & Essential & $\begin{array}{l}\text { Will require immediate freezing- } \\
\text { discuss with laboratory. } \\
\text { Intraosseous samples not suitable }\end{array}$ \\
\hline Free fatty acids/NEFA & $\begin{array}{l}\text { Blood } \\
\text { Fluoride oxalate }\end{array}$ & Hyperinsulinism (low) & Essential & \\
\hline 3HB/ketones & $\begin{array}{l}\text { Blood } \\
\text { Fluoride oxalate }\end{array}$ & $\begin{array}{l}\text { Hyperinsulinism (low) } \\
\text { Fatty acid oxidation } \\
\text { disorders (low) } \\
\text { Ketogenesis defects (low) } \\
\text { Ketolysis defects (high) }\end{array}$ & Essential & $\begin{array}{l}\text { Ratio of FFA/3HB indicative of } \\
\text { disorder of FAO or ketone } \\
\text { metabolism }\end{array}$ \\
\hline Organic acids & Urine & $\begin{array}{l}\text { FAOD } \\
\text { Organic acidaemias }\end{array}$ & Essential & $\begin{array}{l}\text { Ideally collect the next urine } \\
\text { passed }\end{array}$ \\
\hline Blood gas & Blood & $\begin{array}{l}\text { Organic acidaemias } \\
\text { Causes of lactic acidosis }\end{array}$ & Preferable & \\
\hline Lactate & $\begin{array}{l}\text { Blood } \\
\text { Fluoride oxalate }\end{array}$ & $\begin{array}{l}\text { Glycogen storage disorders } \\
\text { Gluconeogenic defects } \\
\text { Mitochondrial disease }\end{array}$ & Preferable & \\
\hline Amino acids & Blood & $\begin{array}{l}\text { Organic acidaemias } \\
\text { Liver dysfunction }\end{array}$ & Preferable & \\
\hline Ammonia & Blood & HIHA & Preferable & \\
\hline Growth hormone & $\begin{array}{l}\text { Blood } \\
\text { Serum }\end{array}$ & $\begin{array}{l}\text { GH deficiency } \\
\text { Hypopituitarism }\end{array}$ & Preferable & $\begin{array}{l}\text { Low levels of GH at the time of } \\
\text { hypoglycaemia warrant liaison } \\
\text { with endocrinology and further } \\
\text { confirmatory testing }\end{array}$ \\
\hline Cortisol & Blood & $\begin{array}{l}\text { Adrenal insufficiency } \\
\text { Hypopituitarism }\end{array}$ & Preferable & $\begin{array}{l}F / U \text { short Synacthen test } \pm V L C F A \\
\text { in boys }\end{array}$ \\
\hline Acylcarnitines & Blood/DBS & $\begin{array}{l}\text { FAOD } \\
\text { Organic acidaemias }\end{array}$ & Not essential & \\
\hline $\begin{array}{l}\text { Thyroid-stimulating } \\
\text { hormone }\end{array}$ & Blood & Hypopituitarism & Not essential & $\begin{array}{l}\text { Interpret with caution in sick } \\
\text { children and in conjunction with } \\
\text { other pituitary tests }\end{array}$ \\
\hline Liver function & Blood & $\begin{array}{l}\text { Liver failure (including metabolic } \\
\text { causes such as galactosaemia, } \\
\text { tyrosinaemia type } 1, \\
\text { mitochondrial disorders) }\end{array}$ & Not essential & \\
\hline $\begin{array}{l}\text { Renal function/ } \\
\text { electrolytes }\end{array}$ & Blood & Adrenal insufficiency & Not essential & \\
\hline
\end{tabular}

3HB, 3-hydroxybutyrate; DBS, dried blood spot; F/U, follow-up; FAOD, fatty acid oxidation defects; GH, growth hormone; HIHA, hyperinsulinismhyperammonaemia syndrome syndrome; NEFA, non-essential fatty acids; UCED, urea cycle enzyme defects; VLCFA, very long chain fatty acids.

Acylcarnitines, urine organic acids and plasma quantitative amino acids were unremarkable.

Interpretation: The results of the fast indicate that the subject was hypoglycaemic at 16 hours after the commencement of the fast. At the time of hypoglycaemia, there is an appropriate increase in the levels of free fatty acids and ketone bodies indicative of normal lipolysis and $\beta$-oxidation of fatty acids during fasting. The postprandial samples show a decrease in the levels of free fatty acids and ketone bodies, which again is in keeping with the normal physiological response.
The results also demonstrate a normal response in the levels of insulin, $\mathrm{C}$ peptide and growth hormone at the time of hypoglycaemia.

We can now conclude that the subject has idiopathic recurrent ketotic hypoglycaemia of childhood having excluded an underlying metabolic or endocrine cause for hypoglycaemia.

\section{3) Fatty acid oxidation disorder}

A girl aged 7 years with very long chain acyl-CoA dehydrogenase deficiency was electively admitted for 
A

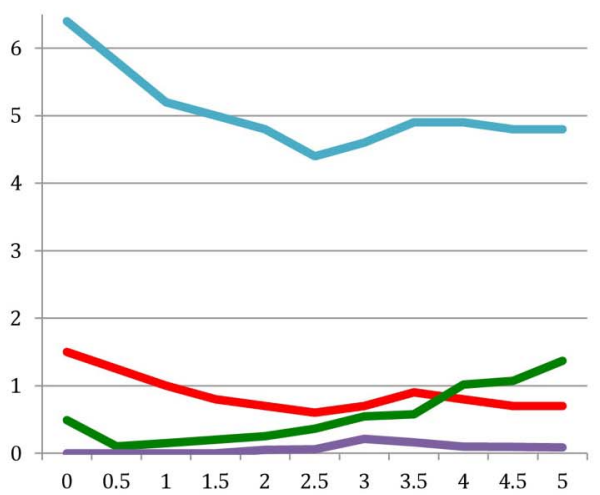

B

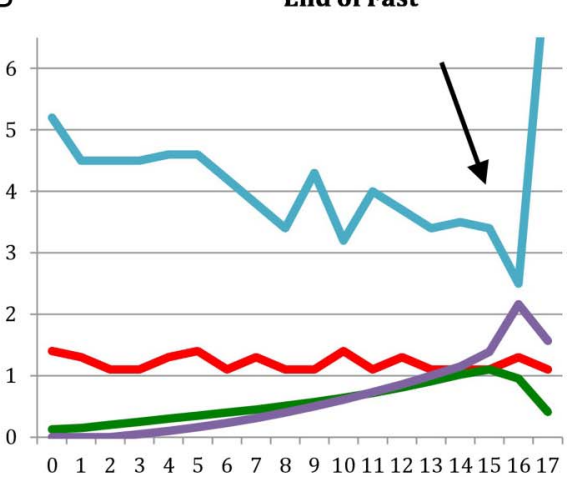

C

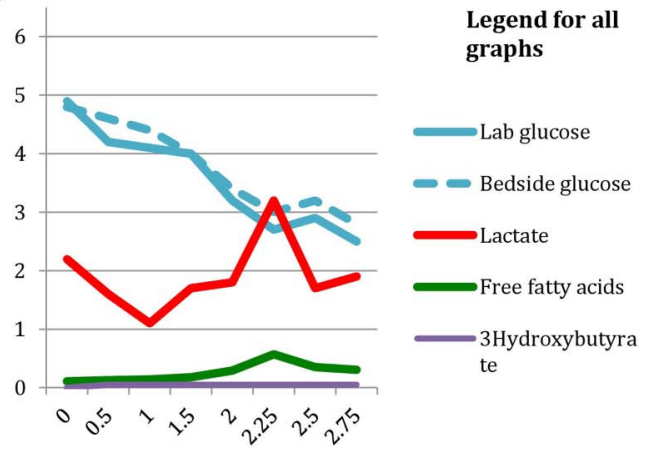

Horizontal axis

Time (hrs)

Vertical axis

Metabolite concentration

(mmol/l)

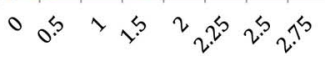

Figure 2 Controlled fasts scenarios.

Table 2 Changes in predominant fuel supply during fasting

\begin{tabular}{lll}
\hline $\begin{array}{l}\text { Duration of } \\
\text { fasting } \\
\text { (hours) }\end{array}$ & $\begin{array}{l}\text { Predominant } \\
\text { fuel }\end{array}$ & $\begin{array}{l}\text { Conditions associated with } \\
\text { impaired fasting tolerance } \\
\text { of this duration }\end{array}$ \\
\hline $0-2$ & Glucose & Hyperinsulinism \\
$2-6$ & Glycogen & GSD \\
$6-12$ & Gluconeogenesis & GSD 0 \\
& $\begin{array}{ll}\text { B-Oxidation of } \\
\text { fatty acids }\end{array}$ & FAOD of gluconeogenesis \\
& GH/cortisol deficiency \\
\hline
\end{tabular}

De Leon et al. ${ }^{12}$

FAOD, fatty acid oxidation disorder; GH, growth hormone; GSD, glycogen storage disorder.

a 6-hour controlled fast for assessment of her safe fasting tolerance.

The results of the fast are shown in table 7 and figure $2 \mathrm{~A}$.

Interpretation: Though this subject did not go hypoglycaemic during the fast, the free fatty acids show a significant rise from 4 hours onwards without corresponding ketone production. The normal molar ratio of free fatty acids to 3 -hydroxybutyrate is $<2$. It is clear that the ratio is very high in this subject (15.7 at 5 hours).

The free fatty acids (in this patient, likely to be all long chain fatty acids) can form toxic intermediates, which can cause potentially lifethreatening encephalopathy, liver failure and
Therefore, the safe fasting tolerance is only 4 hours in this subject.

\section{CLINICAL QUESTIONS}

Should a controlled fast be performed in any child with suspected hypoglycaemia without a documented hyposcreen?

In children with documented or suspected hypoglycaemia, ideally the aetiology of hypoglycaemia is best investigated by analysing hormone and metabolite concentrations in blood and organic acids in urine at the time of hypoglycaemia. While many metabolic disorders can still be diagnosed from random samples, diagnosis of some, especially endocrine disorders, becomes difficult if the required samples are not taken at the time of hypoglycaemia. Under such circumstances, a controlled fast may help to elucidate the underlying cause of hypoglycaemia. If there is no clear evidence of a metabolic or endocrine defect from the baseline tests, the decision to do a controlled fast should be based on the age of the child, presence of symptoms and the frequency of attacks.

An acylcarnitine profile should always be analysed prior to organising a controlled fast as fasting can be dangerous in children with fatty acid oxidation defects. Impaired ketogenesis in these children results in accumulation of fatty acids and toxic acylcarnitine metabolites, which can lead to encephalopathy and death if not treated promptly. There are case reports of children with medium chain acyl-CoA dehydrogenase deficiency, who have died as a result of prolonged 
Table 3 Duration of fasts according to age distribution ${ }^{1}$

\begin{tabular}{llllll}
\hline Age & $<6$ months & $6-8$ months & $8-12$ months & $1-2$ years & $>2$ years \\
\hline Duration of fast & 8 hours $^{*}$ & 12 hours & 16 hours & 18 hours & 20 hours
\end{tabular}

Morris et al. ${ }^{1}$

*Duration of fast in infants $<6$ months of age should be determined based on weight and input from specialists.

Table 4 Example of specimens taken during a controlled fast

\begin{tabular}{|c|c|c|c|c|c|c|}
\hline Specimen & Test & $\begin{array}{l}\text { Baseline } \\
\text { sample }\end{array}$ & $\begin{array}{l}\text { Postprandial } \\
\text { sample }\end{array}$ & $\begin{array}{l}\text { Samples at regular } \\
\text { intervals }\end{array}$ & $\begin{array}{l}\text { End of fast } \\
\text { samples }\end{array}$ & $\begin{array}{l}\text { Post end of fast } \\
\text { samples }\end{array}$ \\
\hline \multirow[t]{11}{*}{ Blood } & $\begin{array}{l}\text { Bedside glucose } \\
\text { (1 hourly) }\end{array}$ & $\checkmark$ & $\checkmark$ & $\checkmark$ & $\checkmark$ & $\checkmark$ \\
\hline & $\begin{array}{l}\text { Lab glucose and } \\
\text { lactate }\end{array}$ & $\checkmark$ & $\checkmark$ & $\checkmark$ & $\checkmark$ & $\checkmark$ \\
\hline & Free fatty acids & $\checkmark$ & $\checkmark$ & $\checkmark$ & $\checkmark$ & $\checkmark$ \\
\hline & 3-Hydroxybutyrate & $\checkmark$ & $\checkmark$ & $\checkmark$ & $\checkmark$ & $\checkmark$ \\
\hline & Insulin & & & & $\checkmark$ & \\
\hline & Growth hormone & & & & $\checkmark$ & $\checkmark$ \\
\hline & Cortisol & $\checkmark$ & & & $\checkmark$ & \\
\hline & Amino acids & $\checkmark$ & & & $\checkmark$ & \\
\hline & Liver function tests & $\checkmark$ & & & $\checkmark$ & \\
\hline & Ammonia and $\mathrm{TCO}_{2}$ & $\checkmark$ & & & $\checkmark$ & \\
\hline & $\begin{array}{l}\text { Carnitine and } \\
\text { acylcarnitine }\end{array}$ & $\checkmark$ & $\checkmark$ & & $\checkmark$ & \\
\hline
\end{tabular}

Urine

Amino acids and organic acids

Collect aliquots of all urine passed from the beginning of the fast and the first and

second urines after the end of the fast. Label carefully with the time and store

separately in fridge so that the end of fast specimens can be identified and analysed.

Urine amino acids: helpful in diagnosing aminoacidopathies.

Postprandial samples: samples taken 1-2 hours postcommencement of the fast. These samples are physiological postprandial samples as the fast commences after the patient is given a meal.

Post end of fast samples: samples taken after termination of controlled fast.

Table 5 Results from a controlled fast in a 9-month-old with glycogen storage disease type 1

\begin{tabular}{|c|c|c|c|c|c|}
\hline Time & $\begin{array}{l}\text { Lab glucose } \\
\text { (mmol/L) }\end{array}$ & $\begin{array}{l}\text { Bedside glucose } \\
\text { (mmol/L) }\end{array}$ & Lactate $(\mathrm{mmol} / \mathrm{L})$ & $\begin{array}{l}\text { Free fatty } \\
\text { acids ( } \mu \mathrm{mol} / \mathrm{L})\end{array}$ & $\begin{array}{l}\text { 3-Hydroxybutyrate } \\
\text { ( } \mu \mathrm{mol} / \mathrm{L})\end{array}$ \\
\hline Baseline & 4.9 & 4.8 & 2.2 & 111 & $<50$ \\
\hline $30 \mathrm{~min}$ & 4.2 & 4.6 & 1.6 & 126 & $<50$ \\
\hline $60 \mathrm{~min}$ & 4.1 & 4.4 & 1.1 & 143 & $<50$ \\
\hline $90 \mathrm{~min}$ & 4.0 & 4.0 & 1.7 & 180 & $<50$ \\
\hline 2 hours & 3.2 & 3.4 & 1.8 & 291 & $<50$ \\
\hline 2 hours $15 \mathrm{~min}$ & 2.7 & 3.0 & 3.2 & 573 & $<50$ \\
\hline 2 hours $30 \mathrm{~min}$ & 2.9 & 3.2 & 1.7 & 350 & $<50$ \\
\hline 2 hours $45 \mathrm{~min}$ & 2.5 & 2.8 & 1.9 & 308 & $<50$ \\
\hline
\end{tabular}

controlled fasts and those with very long chain acyl-CoA dehydrogenase deficiency, where fasting provoked rhabdomyolysis. ${ }^{1}$ Fatty acid oxidation defects can now be diagnosed with the help of tandem mass spectrometry which is a much safer method.

Morris et $a l^{1}$ reviewed 138 controlled fasts organised over a 30 -month period in a tertiary metabolic centre. $54(39 \%)$ resulted in hypoglycaemia and a specific endocrine or metabolic cause was identified in 30 (21\% of all fasts) patients. The diagnostic yield was highest in young children, specific defects being identified in 14 of the 32 children fasted at the age of $<1$ year. As expected, disorders were identified more frequently if hypoglycaemia had been documented at the referring hospital than if it was merely suspected. The diagnostic yield now would be expected to be 


\section{Interpretations}

Table 6 Results from a controlled fast in a 3-year-old with ketotic hypoglycaemia

\begin{tabular}{|c|c|c|c|c|c|c|c|c|}
\hline \multirow{2}{*}{$\frac{\text { Date }}{24 / 3 / 15}$} & \multicolumn{2}{|r|}{ Time } & $\begin{array}{l}\text { Glucose } \\
\text { (mmol/L) }\end{array}$ & $\begin{array}{l}\text { Lactate } \\
(\mathrm{mmol} / \mathrm{L})\end{array}$ & \multicolumn{2}{|l|}{$\begin{array}{l}\text { Free fatty acids } \\
(\mu \mathrm{mol} / \mathrm{L})\end{array}$} & \multicolumn{2}{|c|}{$\begin{array}{l}\text { 3-Hydroxybutyrate } \\
\text { ( } \mu \mathrm{mol} / \mathrm{L})\end{array}$} \\
\hline & & $\begin{array}{l}\text { 13:00 } \\
\text { (baseline) }\end{array}$ & 5.2 & 1.4 & 125 & & $<50$ & \\
\hline \multirow{3}{*}{\multicolumn{2}{|c|}{ Start of the fast }} & 19:00 & 4.7 & & & & & \\
\hline & & $20: 00$ & 4.5 & & & & & \\
\hline & & $21: 00$ & 4.5 & & & & & \\
\hline \multirow[t]{10}{*}{ 25/3/15 } & & $00: 00$ & 4.6 & & & & & \\
\hline & & 01:00 & 4.2 & & & & & \\
\hline & & 03:00 & 3.4 & & & & & \\
\hline & & 04:00 & 4.3 & & & & & \\
\hline & & 05:00 & 3.2 & & & & & \\
\hline & & 06:00 & 4.0 & & & & & \\
\hline & & 07:00 & 3.7 & & & & & \\
\hline & & 08:00 & 3.4 & & & & & \\
\hline & & 09:00 & 3.5 & & & & & \\
\hline & & $10: 00$ & 3.4 & 1.1 & 1103 & & 1390 & \\
\hline 16 hours & & $11: 00$ & 2.5 & 1.3 & 955 & & 2161 & \\
\hline \multicolumn{2}{|l|}{ Postprandial } & $12: 45$ & 7.9 & 1.1 & 411 & & 1569 & \\
\hline Date & Time & $\begin{array}{l}\text { Cortisol } \\
\text { (nmol/L) }\end{array}$ & $\begin{array}{l}\text { Growth hormone } \\
\text { (mU/L) }\end{array}$ & $\begin{array}{l}\text { Insulin } \\
\text { (mlU/L) }\end{array}$ & $\begin{array}{l}\text { C peptide } \\
\text { (nmol/L) }\end{array}$ & $\begin{array}{l}\text { Ammoniz } \\
(\mu \mathrm{mol} / \mathrm{L})\end{array}$ & & $\begin{array}{l}\mathrm{TCO}_{2} \\
(\mathrm{mmol} / \mathrm{L})\end{array}$ \\
\hline 24/3/15 & $\begin{array}{l}\text { 13:00 } \\
\text { (baseline) }\end{array}$ & 123 & 2 & & & 48 & & 24.3 \\
\hline \multirow[t]{3}{*}{ 25/3/15 } & 09:00 & 458 & 4.6 & & & 53 & & 17.8 \\
\hline & $11: 00$ & 674 & 7.4 & $<10$ & $<94$ & 61 & & 16.9 \\
\hline & $12: 45$ & & 1.7 & & & & & \\
\hline
\end{tabular}

Table 7 Results of a controlled fast in a 7 year old with VLCADD deficiency

\begin{tabular}{|c|c|c|c|c|}
\hline Time & $\begin{array}{l}\text { Glucose } \\
\text { (mmol/L) }\end{array}$ & $\begin{array}{l}\text { Lactate } \\
\text { (mmol/L) }\end{array}$ & $\begin{array}{l}\text { Free fatty } \\
\text { acids( } \mu \mathrm{mol} / \mathrm{L})\end{array}$ & $\begin{array}{l}\text { 3-Hydroxybutyrate } \\
\text { ( } \mu \mathrm{mol} / \mathrm{L})\end{array}$ \\
\hline Baseline & 6.4 & 1.5 & 489 & $<50$ \\
\hline 1 hour & 5.2 & 1.0 & & \\
\hline 1 hour 30 min & 5.0 & 0.8 & & \\
\hline 2 hours & 4.8 & 0.7 & & \\
\hline 2 hours $30 \mathrm{~min}$ & 4.4 & 0.6 & 361 & 58 \\
\hline 3 hours & 4.6 & 0.7 & 544 & 211 \\
\hline 3 hours $30 \mathrm{~min}$ & 4.9 & 0.9 & 577 & 160 \\
\hline 4 hours & 4.9 & 0.8 & 1015 & 96 \\
\hline 4 hours $30 \mathrm{~min}$ & 4.8 & 0.7 & 1071 & 94 \\
\hline 5 hours & 4.8 & 0.7 & 1370 & 87 \\
\hline
\end{tabular}




\section{Clinical bottom line}

- Diagnosis of endocrine disorders causing hypoglycaemia may be missed if samples are not taken at the time of hypoglycaemia.

- In the absence of a hypoglycaemia screen, a controlled fast should be undertaken based on the individual clinical situation. It can be valuable in determining the maximum safe interval between feeds and prevent further hypoglycaemic episodes.

- Acylcarnitine profile should be confirmed to be normal prior to organising a controlled fast.

lower due to the wider availability of metabolic tests such as acylcarnitine profiles that can diagnose inborn errors of metabolism without the need for controlled fasting.

Controlled fasts can also help the family and clinician in determining the safe fasting tolerance of the child when well and tailor dietary management.

\section{Is a controlled fast indicated in a neonate with high glucose requirement and in whom the opportunity was missed to do a hypoglycaemia screen?}

The normal glucose requirement in a neonate is 4-8 $\mathrm{mg} / \mathrm{kg} / \mathrm{min}$. Hyperinsulinism should be considered in a neonate when the glucose requirement is $>10 \mathrm{mg} /$ $\mathrm{kg} / \mathrm{min}$. It should be considered in any neonate with persistent or frequent hypoglycaemic episodes.

Hyperinsulinism is a predominant cause of profound hypoglycaemia in the neonatal period, which, if untreated, can lead to significant morbidity and mortality. Studies have shown that recurrent spontaneous hypoglycaemia may not be accompanied by recognised neuroglycopenic symptoms in infants with congenital hyperinsulinism. ${ }^{5}$ Therefore, it is important to have a high index of suspicion of hyperinsulinism in a neonate with hypoglycaemia and high glucose requirement.

Hyperinsulinism is diagnosed by the finding of detectable insulin levels, low free fatty acid concentrations and low ketones at the time of hypoglycaemia. Hence, a hypoglycaemia screen would be ideal in diagnosing hyperinsulinism.

A controlled fast is not necessarily indicated in neonates with hyperinsulinism in whom the diagnosis can

\section{Clinical bottom line}

- Hyperinsulinism should be considered in any neonate with persistent or frequent hypoglycaemic episodes and in whom the glucose requirement is $>10 \mathrm{mg} / \mathrm{kg} / \mathrm{min}$.

- Close liaison with an endocrinologist is useful in managing hypoglycaemia secondary to hyperinsulinism, especially the refractory cases who may need specific therapy as diazoxide and chlorthiazide. be made based on the high glucose requirement and widely available assays to measure insulin at the time of hypoglycaemia. Fasting can be dangerous in these subjects as they cannot produce ketones, which can be used as alternative sources of energy supply. Specialist endocrine input should be sought in all cases of suspected hyperinsulinism, who did not have a hyposcreen, to guide further management.

\section{Is a controlled fast indicated in a child with} hypoglycaemia secondary to illness?

Hypoglycaemia secondary to an intercurrent illness like diarrhoea and vomiting in a child is a common scenario in paediatric emergency department. Ideally, every attempt should be made to collect crisis samples at the time of hypoglycaemia and the next available urine collected for analysis of ketones and organic acids.

However, it is important to establish whether children are ketotic at the time of hypoglycaemia. In the review by Morris et al, ${ }^{1} 32$ (59\%) children who became hypoglycaemic during the fast had 'ketotic hypoglycaemia'.

Idiopathic ketotic hypoglycaemia (IKH) is the most frequent term used to describe recurrent hypoglycaemia in children aged between 1 and 5 years. ${ }^{13}$ The clinical pattern was characterised by Colle and Ulstrom as the tendency of affected children to become ketotic and hypoglycaemic during a low calorie ketogenic diet. ${ }^{11}$ It is due to the failure of hepatic glucose production to meet the body's increase in glucose demand during illness or fasting. ${ }^{13} 14$ IKH typically improves with age and is not usually observed after children reach puberty.

Recurrent episodes necessitate baseline metabolic investigations including an acylcarnitine profile prior to controlled fast. In cases with recurrent episodes or symptomatic hypoglycaemia, metabolic specialist opinion should be sought regarding further management. X-linked adrenoleukodystrophy should always be considered in a boy with recurrent episodes of hypoglycaemia and low cortisol levels.

Controlled fasts should be considered in children with clinical features of a primary endocrine or metabolic defect or in those with recurrent symptomatic hypoglycaemia.

Controlled fasts can also be helpful in determining the fasting tolerance in suspected cases of primary endocrine or metabolic disorder.

\section{Clinical bottom line}

$\mathrm{IKH}$ is common in childhood but it is a diagnosis of exclusion.

- In the absence of a hyposcreen, the decision to undertake a controlled fast should be taken based on individual clinical situation and after close liaison with metabolic specialists. 


\section{SUMMARY}

Controlled fasts can play a valuable role in the diagnosis and management of hypoglycaemia in paediatric clinical practice, but are no substitute for the collecting of appropriate critical samples at the time of hypoglycaemia for metabolic and endocrine studies. Fatty acid oxidation defects, hyperinsulinism and adrenal insufficiency should always be excluded prior to organising controlled fasts.

Controlled fasts are safe if conducted in an experienced setting with strict protocols in place. Failure to adhere to protocol can defeat the purpose of the study and can potentially be dangerous.

Proper planning in conjunction with the laboratory and close supervision by staff experienced in controlled fasts is crucial to ensure the best quality information is yielded from these procedures.

Contributors SSr: written the article. SSa: contributed to design and presentation of the data, gave ideas for the scenarios, critically reviewed the paper and finalised it. JR: reviewed the clinical questions and also helped with the design and presentation of the data. SV: reviewed the paper. MAP: reviewed relevant literature, contributed to design and presentation of the data and offered ideas for the scenario.

Competing interests None declared.

Provenance and peer review Commissioned; externally peer reviewed.

\section{REFERENCES}

1 Morris AA, Thekekara A, Wilks Z, et al. Evaluation of fasts for investigating hypoglycaemia or suspected metabolic disease. Arch Dis Child 1996;75:115-9.

2 Alkén J. Glucose and Ketone Body Metabolism: With Emphasis on Ketotic Hypoglycaemia [thesis]. Stockholm, Sweden: Karolinska Institute, 2008. http://diss.ki.b.ki.se/2008/ 978-91-7357-502-7/thesis.pdf

3 Daly LP, Osterhoudt KC, Weinzimer SA. Presenting features of idiopathic ketotic hypoglycaemia. J Emerge Med 2003;25:39-43.
4 Lucas A, Morley R, Cole TJ. Adverse neurodevelopmental outcome of moderate neonatal hypoglycaemia. BMJ 1988;297:1304-8.

5 Christesen HT, Brusgaard K, Hussain K. Recurrent spontaneous hypoglycaemia causes loss of neurogenic and neuroglycopaenic signs in infants with congenital hyperinsulinism. Clin Endocrinol (Oxf) 2012;76: 548-54.

6 Thornton PS, Stanley CA, De Leon DD, et al, Pediatric Endocrine Society. Recommendations from the Pediatric Endocrine Society for evaluation and management of persistent hypoglycemia in neonates, infants, and children. J Pediatr 2015;167:238-45.

7 Stanley CA, Rozance PJ, Thornton PS, et al. Re-evaluating "transitional neonatal hypoglycemia": mechanism and implications for management. J Pediatr 2015;166: 1520-5.e1.

8 Güemes M, Rahman SA, Hussain K. What is a normal blood glucose? Arch Dis Child 2016;101:569-74.

9 Ghosh A, Banerjee I, Morris AA. Recognition, assessment and management of hypoglycaemia in childhood. Arch Dis Child 2016;101:575-80.

10 Bonnefont JP, Specola NB, Vassault A, et al. The fasting test in paediatrics: application to the diagnosis of pathological hypo- and hyperketotic states. Eur J Pediatr 1990;150:80-5.

11 Chaussain JL. Glycemic response to 24 hour fast in normal children and children with ketotic hypoglycaemia. J Paediatr 1973;82:438-43.

12 De Leon D, Stanely CA, Sperling MA. Hypoglycaemia in neonates and infants. In: Sperling MA, ed. Pediatric endocrinology. 3rd edn. Saunders Elsevier, 2008:889, 165-197. ISBN 978-1-4160-4090-3.

13 Huidekoper HH, Duran M, Turkenburg M, et al. Fasting adaptation in idiopathic ketotic hypoglycaemia: a mismatch between glucose production and demand. Eur J Pediatr 2008;167:859-65.

14 Bodamer OA, Hussein K, Morris AA, et al. Glucose and leucine kinetics in idiopathic ketotic hypoglycaemia. Arch Dis Child 2006;91:483-6. 